Обрезан А. Г. ${ }^{1,2}$, Щербакова Н. В. ${ }^{1}$

${ }^{1}$ ГОУ ВПО «Санкт-Петербургский госуАарственный университет», Россия

${ }^{2}$ МежАународный медицинский центр «СОГАЗ», Санкт-Петербург, Россия

\title{
ПАТОГЕНЕТИЧЕСКИЕ МЕХАНИЗМЫ
}

\section{РАЗВИТИЯ ПАТО ОГИИ МИОКАРАА У БОАЬНЫХ СО ЗАОКАЧЕСТВЕННЫМИ НОВООБРАЗОВАНИЯМИ: СОВРЕМЕННОЕ СОСТОЯНИЕ ПРОБАЕМЫ}

МиокарА, обладающий высокой метаболической активностью, реагирует на нарушения обмена веществ и энергетический Аисбаланс поА Аействием растущего зАокачественного новообразования. Кроме того, сама опухоль способна продуцировать вещества, оказывающие непосредственное влияние на обменные процессы и жизненный цикл не затронутых опухолевым процессом клеток, в том числе кардиомиоцитов. В обзоре резюмированы и систематизированы имеющиеся на сегоАняшний день Аанные исследований, посвященных отАельным аспектам поврежАающего Аействия онкогенов и факторов, связанных с опухолевым процессом, на сердечную мышцу, морфофункциональным изменениям со стороны серАечно-сосуАистой системы онкологических пациентов, подробно описаны патогенетические механизмы их развития.

Ключевые слова

Вторичные поражения миокарда; кардиомиопатия у онкологических больных; метаболические изменения у онкологических больных

Аля циитирования

Obrezan A. G., Shcherbakova N. V. Pathogenetic mechanisms of development of myocardial pathology in patients with malignant tumors: the current state of the problem. Kardiologiia. 2020;60(2):142154. [Russian: Обрезан А. Г., Щербакова Н.В. Патогенетические механизмы развития патологии миокарАа у больных со зАокачественными новообразованиями: современное состояние проблемы. КарАиология. 2020;60(2):142-154]

Автор дяя переписки Щербакова Наталья Владимировна. E-mail: dr-lnv@yandex.ru

$\mathrm{B}$ 1968 году G.E. Burch с соавт. опубликовали данные исследования, в котором показали, что масса сердца у пациентов, умерших в результате онкологического забомевания, меньше, чем среднепопумяционная [1]. В 1980 г. более чем на 4700 аутопсийных исследованиях L. Houten и A.A. Reilley выявили, что среди умерших со змокачественными новообразованиями (3НО) в $11 \%$ скучаев причиной смерти была сердечно-сосудистая патология. Чаще всего наблюАались инфекционное поражение серАца, мекарственно-индуцированная кардиотоксичность, электролитные нарушения, однако в $20 \%$ скучаев причиной смерти бымо нарушение сердечной функции, ассоциированное с опухолью [2]. В исследовании R. Mamidanna cepдечные причины смерти регистрировались в $13,5 \%$ (в течение 30 Аней после селективной резекции колоректального рака) и 5,7\% скучаев (в течение года после резекции) у пациентов до 65 мет (при преАшествующей сопутствующей серАечной патологии у 5,2\%), в то время как в той же возрастной группе смертность от сердечной патологии составмяет всего 0,4-0,5\% [3]. Это свидетельствует о том, что причинами сердечной смерти у онкологических больных являются не только последствия предшествующих кардиоваскулярных заболеваний. W. McBride и его группа выявили, что у $50 \%$ больных со множественной миеломой на фоне опухолевого процесса развивалась сердечная недостаточность (СН) [4]. С. Drott и K. Lundholm выявили снижение потребления кислорода миокардом на экспериментальной модели рака [5].
В многочисленных работах описываются клинические проявления поражения сердечно-сосудистой системы у онкологических больных, характерные гистомогические, умьтраструктурные изменения и нарушение биохимизма кардиомиоцитов, однако терминология Амя обозначения этой патомогии не явмяется общепринятой. В зарубежной китературе разные авторы обозначают нарушение структуры и функции серАца, ассоциированное с течением опухолевого процесса, как «сердечная атрофия» (cardiac atrophy), «опухоль-ассоциированная кардиомиопатия» (cancer-associated cardyomyopathy), «сердечная кахексия» (cardiac cachexia), атрофическое ремоделирование миокарда (cardiac atrophic remodeling), а иногаа авторы вовсе избегают отчетливого определения этой патологии, употребляя словосочетания «повреждение сердца/миокарда» (cardiac injury или altered cardiac muscle). По нашему мнению, к обозначению комплекса структурных и метаболических изменений серАца при онкопатологии поАходит термин «карАиомиопатия» (КМП). Согласно определению, преАложенному в 2006 году Американской кардиологической ассоциацией (ААC), наиболее принятому сегодня в мире и взятому за основу в руководстве по кардиологии Всероссийского научного общества кардиологов (ВНОК) 2010 гоАа, «КМП - гетерогенная группа заболеваний различной этиологии (часто генетически обусловленных), сопровожАающихся механической и/или электрической Аисфункцией миокарда и (в ряде случаев) непропорцио- 
намьной гипертрофией или Аиматацией» $[6,7]$. Учитывая, что течение опухолевого процесса сопровожАается комплексом доказанных на экспериментальных моделях и в клинических исследованиях структурных и функциональных изменений сердечной мышцы, мы считаем корректным использование термина «кардиомиопатия» Аля обозначения патологии серАца, вызванной наличием ЗНО. Тем не менее индуцированная опухолевым процессом КМП, как и многие Аругие вторичные КМП, не нашиа своего места в классификации Всемирной Организации ЗАравоохранения 1995 года. Также и в более позАней классификации ААС (2006) среАи множества размичных этиопатогенетических вариантов КМП, развивающаяся у онкологических больных, не отражена. В то же время патогенетические механизмы поражения миокарАа при онкологических процессах, несомненно, нацеливают на терминологическое применение КМП.

\section{Общие механизмы вАияния опухоми}

\section{на метабомизм и энергетику карАиомиоцитов}

Опухолевые процессы в той или иной степени привоАят к нарушению обмена веществ и энергетическому Аисбалансу, что обусловлено взаимоотношениями зАоровых и малигнизированных клеток. МиокарА, обладающий высокой метаболической активностью и чувствитемьный к нейрогуморальным вмияниям, безусловно, реагирует на изменения гомеостаза под Аействием растущего $3 \mathrm{HO}$. Развивающиеся изменения электролитного, белкового, мипиАного, углеводного обменов, коагумопатия, эндогенная интоксикация продуктами распаАа опухоми, анемия, гормональные и иммунологические нарушения способны негативно вмиять на метаболизм и энергетику карАиомиоцитов, привоАя впослеАствии к Аисфункции и структурным изменениям серАца.

\section{Нарушение углеводного обмена при $3 \mathrm{HO}$ и его влияние на кардиомиоциты}

Первые исследования, посвященные проблемам взаимодействия интактных и опухолевых клеток в организме, появились в начале XX века, на заре становления биохимии как отАемьной науки. Именно тогАа бымо показано, что рост опухоми сопровожАается повышенным потребцением глюкозы и кислородным голоданием, причем в опытах in vitro доказана более высокая жизнеспособность малигнизированных клеток по сравнению со зАоровыми в условиях гипоксии и более быстрая утимизация ими глюкозы (эффект Варбурга) [8].

Начиная со второй половины XX века, когАа биохимия прочно укрепилась в ряАах меАико-биологических наук и в ее арсенаме появцялись новые методы исследований, активно разрабатывались размичные теории канцерогенеза, изучались молекумярные механизмы индукции, роста и регумяции $3 \mathrm{HO}$, предметом многих работ стал вопрос о системном Аействии опухолей и патогенетических основах этого влияния. Так, в 1974 году В. С. Шапот, изучая системное Аействие опухоли, отмечац, что она конкурирует с интактными тканями за необходимые Аля ее роста метаболиты (аминокислоты, глюкозу, микроэлементы, нуклеиновые основания, витамины и Ар.), и назвац это феноменом «субстратной мовушки» [9]. Известно, что в озлокачествленных клетках основным источником аденозинтрифосфорной кислоты (АТФ) явмяется гликолиз - неэкономичная форма обеспечения метаболических процессов, так называемый энергетический атипизм опухомевой ткани. Скорость потребления опухолью гмюкозы горазАо больше скорости ее поступления в кровь, что ведет к развитию гипогликемии и к снижению содержания глюкозы в тканях. В ответ на гипогликемический эффект развивается гиперфункция коры наАпочечников. Увеличение секреции глюкокортикоидов, направленное на обеспечение глюконеогенеза, паралмельно приводит к активизации катаболических процессов, усиливая Аистрофические процессы в миокарде. «Гипогликемическое Аавление» служит триггером энергетического Аефицита клеток организма, в том числе карАиомиоцитов, и пусковым механизмом неспецифического Аействия опухоли. Кроме того, у пациентов со $3 \mathrm{HO}$ продемонстрировано развитие инсулинорезистентности, что усугубляет энергетическое голодание тканей [10]. Бомее того, D. Humberstone с соавт. (1988) показами значимую зависимость метаболизма глюкозы и скорости глюконеогенеза от гистологической структуры опухоми. Так, скорость гмюконеогенеза у пациентов с саркомами была в 2-3 раза выше, чем в контрольной группе, а у пациентов с верифицированной мимфомой - значительно не отличалась [11]. Оказалось, что особенности Аисметаболических изменений зависят и от мокамизации новообразования. Так, D. Dempsey (1984) выявиц, что у пациентов со $3 \mathrm{HO}$ органов жекудочно-кишечного тракта активность глюконеогенеза была на 70\% выше, чем у зАоровых миц [12].

\section{Нарушения обмена белков}

как патогенетическиймеханизм КМП, ассоциированной с опухолевым процессом

В течение Алительного времени организм пытается компенсировать системное влияние опухоли, но в конечном итоге это приводит к уменьшению снабжения органов кислородом, иммуносупрессии и Аистрофическим изменениям. Метаболический атипизм проявляется в перестройках, направленных на обеспечение роста $3 \mathrm{HO}$, усиленный синтез онкобелков, приспособление к относительному Аефициту кислорода. Утратившая контроль наА процессами Аеления и апоптоза клетка активно син- 
тезирует эмбриональные белки, изоэнзимы некоторых ферментов и Аругих соединений, обеспечивающих рост новообразования (стимумяторы ангиогенеза и паракринные регумяторы). Попадая в системный кровоток и имея гормоно- и медиаторо-подобные свойства, эти соединения могут вызывать патофизиологические реакции, клинически проявляющиеся симптомами, объединенными в паранеопластический синдром. Высокая активность синтетических процессов в опухоли требует повышенного потребления азотистых оснований, аминокислот (опухоль - «ловушка азотистых соединений») [13]. КАиницистам хорошо известны проявления нарушения белкового обмена у онкологических больных в виде гипоаАьбумин- и гипопротеинемии, прогрессирующего снижения массы тела вплоть до раковой кахексии $[14,15]$. Многие исследователи подтверждают на мабораторных моделях грызунов, что опухолевому процессу и раковой кахексии сопутствует изменение белкового обмена с преобладанием катаболических процессов, что, вкупе с нарушением всасывания и усвоения белков [16], ведет к развитию белковой недостаточности, кахексии и дистрофии миокарАа [17-22].

Кроме неспецифического действия опухоли, заключающегося в конкурентной борьбе малигнизированных клеток за метаболиты, выяснилось, что растущее ЗНО синтезирует само или способствует выработке организмом в ответ на представление опухомевых антигенов специфических сигнальных веществ - цитокинов. РяА исследований подтверАил роль продуцируемых в организме интерлейкинов-1 и 6 (IL-1, IL-6), фактора некроза опухоли- $\alpha$ (TNF- $\alpha)$, интерферона- $\gamma$ (INF- $\gamma$ ) и цитокинов группы факторов роста и имплантации, а также производимых малигнизированными кметками фактора индукции протеасом и АипиА-индуцирующего фактора в развитии дисфункции миокарда на мабораторной модели и у пациентов с раковой кахексией [23]. Известно, что гиперпродукция TNF- $\alpha$ коррелирует с деградацией фибримляного комлагена, активацией апоптоза и гипертрофией кардиомиоцитов. TNF- $\alpha$ и IL-1 связаны с развитием ремоделирования мевого желудочка $(\Lambda Ж)$ и формированием $\mathrm{CH}$ [24]. Взаимодействуя с рецепторами кардиомиоцитов, перечисленные выше провоспалительные цитокины запускают каскадные пути через митоген-активируемый протеинкиназный (МАРК) путь и систему каспаз, что приводит к апоптозу клеток миокарда. Роль цитокинов в развитии КМП на фоне опухолевого процесса показана на модели грызунов. По Аанным отдельных исследований, IL-6 через P44/42 MAPK вмияет на убиктивин-протеасомную систему, ускоряя Аеградацию белков кардиомиоцитов [18]. ВАияние на серин-специфическую IkB киназу (IKK) вызывает фосфорилирование и последующую деграАацию $\mathrm{IkB}$, что, в свою очереАь, вмияет на NF-kappaB (NF-kB) - универсальный фактор транскрипции, контролирующий экспрессию генов иммунного ответа, апоптоза и клеточного цикла. Так как он находится в цитоплазме клетки в неактивном состоянии в комплексе с ингибиторным белком IkB, то деградация IkB приводит к тому, что NF-kB высвобожАается от ингибирующего комплекса, транслоцируется в яАро и активирует транскрипцию контролируемых генов, отвечающих за апоптоз и протеасомную аутофагию. Повышение уровня IL-6 и преАставления его рецептора были выявлены в миокарде мышей минии С-26 [18], в этом же исслеАовании получены данные по активации сигнальных путей, опосредованных NF-кВ и каспазами. ВАияние на NF$\mathrm{kB}$ реализуется и через белок, относящийся к семейству TNF - TNF-связанный индуктор апоптоза (TWEAK) и его рецептор Fn14, их концентрация повышахась и усиливала явления апоптоза кардиомиоцитов в исследовании на экспериментальной модели крыс с раком момочной железы [25]. Течению змокачественной опухоми сопутствует повышение концентрации миостатина, лиганда трансформирующего фактора роста (TGF- $\beta$ ). TGF- $\beta$ нарушает взаимодействие ионов кальция и саркоплазматического ретикулума кардиомиоцитов, что веАет к нарушению сократительной способности серАца [26]. Миостатин, связываясь с активиновым рецептором II типа (ActRIIB), запускает каскадную реакцию с участием белков семейства SMAD, преобразователей сигналов и транскрипционных модуцяторов, в основном экспрессирующихся в миокарАе, скеметной мускулатуре и эндотелиальных кметках. Исследование А.І. Padrao и его группы Аемонстрирует повышение уровня соАержания сигнального белка SMAD-3 у мышей со сниженной массой миокарАа на фоне опухомевого процесca [25]. Функция белков семейства SMAD заключается в регумяции пролиферации, Аифференцировки и апоптоза, в том числе через внутриклеточный сигнальный путь PI3K/Akt/mTOR, и парамлельно они способны активировать протеолиз. Киназы Akt и mTOR не только отвечают за контроль апоптоза, рост, пролиферацию кметок, метаболизм, но и выполняют тканеспецифичную функцию в работе сераца. Кроме того, киназа Akt явмяется функциональным антагонистом фактора транскрипции FoxO1. Эта киназа препятствует транслокации FoxO1 в яАро кметки, запуская через мигазы убиктивинового пути MuRF-1 и атрогин (atrogin-1), убиктивин-зависимую деградацию белков. Участие убиктивин-протеасомной системы (UPS) в развитии атрофии миокарАа при раковой кахексии изучено не Ао конца [27]. В исслеАовании М. Tian с соавт. описано усиление экспрессии атрогина-1 и MuRF-1 и высокий уровень убиктивированных протеинов в миокарде мышей с колоректальным раком (C-26) [18]. Akt и FoxO1 осуществмяют совмест- 
ный контроль наА процессами удержания белка в цитозоле и его транспорта в протеасомы. FoxO1 также регумирует транскрипцию генов инсулиновых рецепторов, опосредуя влияние не только на белковый, но и на углеводный обмен. Рост инсулинорезистентности (снижение концентрации наиболее изученного инсулиноподобного пептиАа IGF-1 и аффинности рецепторов инсулина к своему субстрату) при 3 НО через влияние на белок Akt и 5'-аденозин монофосфат-активируемую киназу (AMPK) способствует ингибиции mTOR и запуску аутофагии [28]. J. Spinger и его комлеги на минии крыс АН130 (модемь гепатоцемлюмярного рака) продемонстрировали торможение синтеза протеинов кардиомиоцитами, развитие раковой кахексии и КМП, коррелирующие со снижением экспрессии инсумина и рецептора инсулиноподобного фактора роста (IGFR) и с уменьшением активности гликоген-синтазной киназы $3 \alpha$, фосфорилирования Akt [20]. Торможение синтеза белков миофибримл, снижение массы миокарда на 6-8\% по сравнению с группой контроля при активации фосфорилирования АМРК и супрессии mTOR было продемонстрировано в исслеАовании N. D. Manne с соавт. на экспериментальной моАели грызунов с колоректальным раком [29]. Аизосомальная аутофагия, убиктивин-зависимая деградация белка протеасомами, каспазо-зависимый протеолиз - все эти пути могут приводить к разрушению миофибримл, что вместе в апоптозом кардиомиоцитов может стать причиной развития КМП. В исслеАованиях на моделях грызунов показано, что при наличии маркеров аутофагии (LC3-II, каталепсин-L, беклин) при экектронной микроскопии выявлялись Авухмембранные аутофагические вакуоли с порциями цитоплазмы, митохонАриями и миелиноподобными структурами внутри [17]. Суммируя Аанные, полученные в различных экспериментальных исследованиях, приводим схему возможных путей влияния цитокинов, синтезируемых при опухолевом процессе, на белковый метаболизм и механизмов реализации поврежАающих влияний на миокарА (рис. 1). Согласно опубликованным работам общие изменения белкового обмена заключаются в увеличении катаболизма мышечного белка, увеличении оборота общего белка организма, приросте синтеза белка в печени, снижении синтеза белка в мышечной ткани $[30,31]$.

\section{Нарушения мипидного обмена и их роль}

\section{в развитии опухоль-ассоциированной КМП}

Опухолевый процесс сопровождается ускоренным метаболизмом жиров, в основном необходимых Аля синтеза мипидных компонентов цитоплазматической мембраны [32]. Бомее 50 мет назаА быми описаны особенности регуляции метаболизма жиров, и было показано, что многие малигнизированные кметки сами способны к синте- зу мипиаов de novo [33]. Они также способны продуцировать соединения, влияющие на активность генов, ответственных за процессы мипидного обмена в интактных опухоли тканях. Все эти процессы направлены на синтез фосфоглицеридов, участвующих в построении мембран клеток, а также в модумяции проницаемости мембран, в синтезе стероидных гормонов и гормонов ренин-ангиотензиновой системы $[34,35]$. Триглицериды и мипопротеиды, претерпевая ряА биохимических изменений, накапливаются в клетках в виде мипидных капель. В исследовании М. Т. Accioly на клеточной кинии аденокарциномы толстой кишки человека показано, что увеличенное соАержание жировых гранул в малигнизированных клетках выше по сравнению со зАоровыми коррелирует со скоростью их пролиферации [36]. Аипиды из этих Аепо могут мобилизоваться через процессы $\beta$-окисления в митохонАриях с выделением необходимой опухолевым клеткам энергии (рис. 1). В этом же исследовании показано, что процессы мобилизации связаны с высоким уровнем активности цитокинов и активируются циклооксигеназой-2 и простагландин-синтазой [37]. Роль $\beta$-окисления, как важного компонента энергетического снабжения роста опухоли, продемонстрирована у пациентов с раком преАстательной [37] и поАжелудочной железы [38]. Большинство ферментов, участвующих в превращениях жирных кислот и холестерина, регулируются специфическими белками - факторами транскрипции SREBPs. Как уже описано выше, онкогенная активация затрагивает ряА каскаАных путей, связанных с Akt, AMPК, Е2F. Эти каскаАные пути явцяются универсальными и способны вмиять не только на белковый, но и на мипидный и угмеводный обмены, ускоряя мипонеогенез с использованием гмюкозы в качестве энергетического субстрата [39, 40]. Причем если активация E2F и повышение уровня мутантного p53 (p53mut), сопутствующие онкогенезу, усиливают экспрессию генов мевалонатного пути биосинтеза хоместерина [41], то АМРК, напротив, активируется в случае недостатка макроэргических фосфатов и направляет мипидный обмен в сторону $\beta$-окисления. Фактор, индуцируемый гипоксией (HIF1), активируется нехваткой кисморода и снижает поступление глюкозы в митохонАрии $[42,43]$. Солидные опухоли, рост которых часто сопровожАается развитием гипоксии в неваскуляризированных участках, способны продолжать рост вне зависимости от их обеспечения кислородом благодаря активации факторов семейства HIF [44, 45].

\section{Нарушение энергетического обмена}

при опухолевом заболевании как основа кардиопатии

Аисбаланс в энергетическом метаболизме миокарАа приводит к сАвигу в системе макроэргических фосфатов с развитием Аефицита АТФ и повышения уровней ме- 
Рисунок 1. Схема влияния на обмен и жизненный цикл карАиомиоцитов сигнацьных путей, активируемых онкогенами и цитокинами

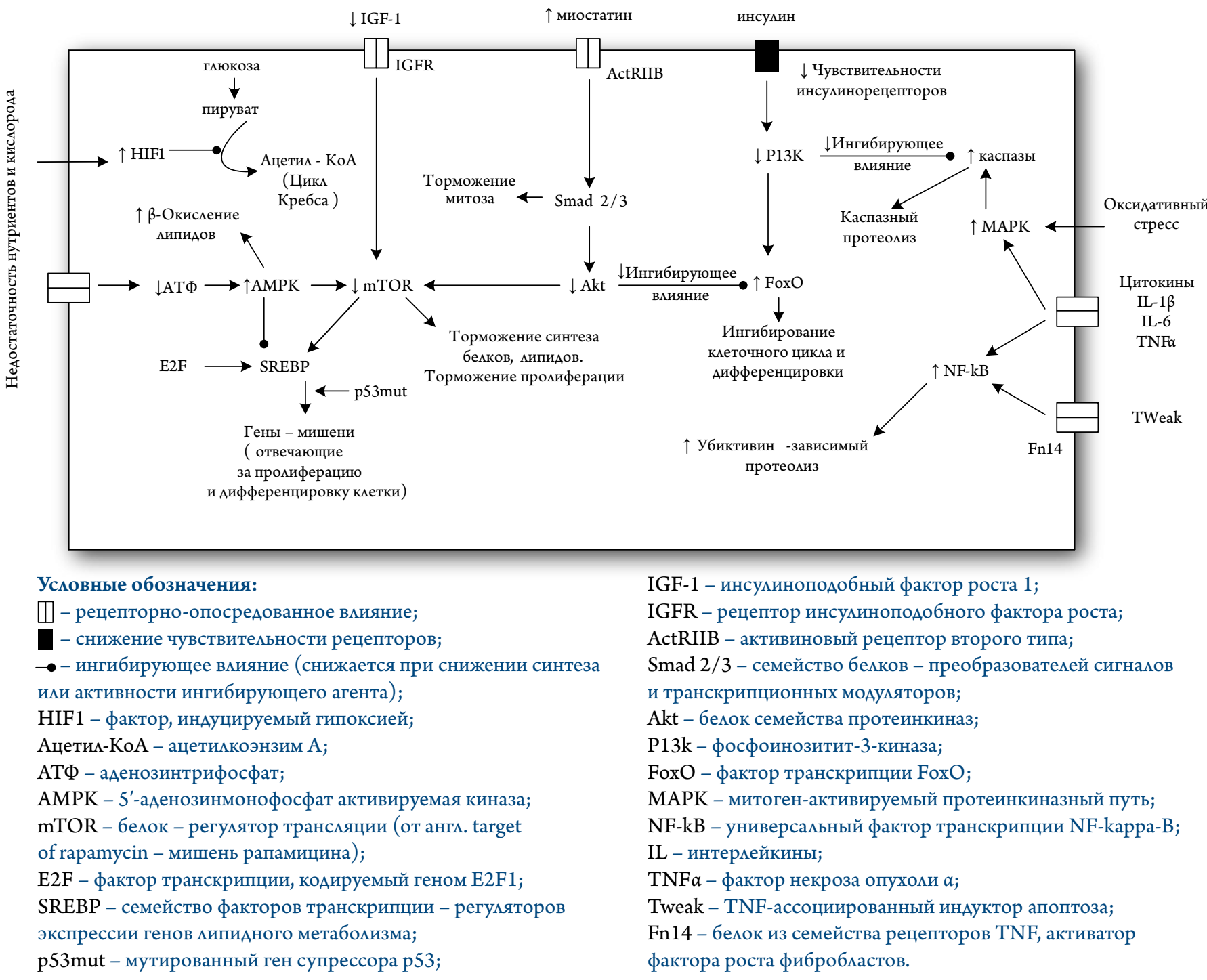

нее энергетически ценных ААФ и АМФ. Важным звеном в нарушении энергетического обмена миокарАа при опухолевой патологии является Аисфункция митохонАрий. В ряде работ сообщается об отражении метаболических нарушений на функциях митохонАрий кардиомиоцитов, что является важным патогенетическим аспектом развития КМП [46]. Начиная с публикаций Варбурга бомее чем 50-летней Аавности, в митературе описаны различные ультраструктурные и цитохимические изменения органем кметки на фоне опухомевого процесса. Бымо выявлено несколько механизмов поврежАающего действия опухолевого процесса на митохонАриальный аппарат окружающих клеток - гипогликемическое Аавмение, гипоксия, разобщение окислительного фосфорилирования (например, при митохондриальном набухании - типовом ответе митохондрий на поврежАение или химическое воздействие продуктов распада опухолевой ткани и патологических соединений, продуцируемых ЗНО) [47]. Известно, что усиленная продукция NF-kB и активация

МАРК опосредованно способны вызывать митохондриальную Аисфункцию [48]. Более того, на крысах минии АН-130 показано сопутствующее прогрессированию ЗНО усиление окисления белков, вовлеченных в гликомитические процессы, распределение и синтез АТФ, осуществляющих сократительную функцию и контролирующих работу митохонАрий [49]. Различают следующие структурные изменения митохондриального аппарата: увеличение их числа и размеров (образование мегамитохонАрий), изменение их формы и структуры крист. Цитохимические сАвиги включают изменение экспрессии и активности субъединиц дыхательной цепи и гликолитических ферментов, снижение активности окислительных процессов NADH-связанных субстратов, появление мутаций матричной дезоксирибонуклеиновой кислоты. Роль этих изменений в развитии опухоли, мекарственной устойчивости, прогрессировании заболевания и метаболических изменениях в организме Ао сих пор до конца не изучена [50]. 
Метаболические нарушения, ассоциированные с течением опухолевого процесса, и их вАияние на миокарА

Изменения метаболического статуса вызывают реактивные изменения в организме, направленные на адаптацию к новым условиям, «диктуемым» жизнедеятельностью новообразования. КАинически и мабораторно они находят отражение в развитии синдромов - недостаточности питания (с крайне выраженной формой - кахексией), анемии, Аисэлектролитемии, гемостазиологических нарушений, нарушении толерантности к углеводам, белкового обмена, метаболического ацидоза, гиперурикемии, иммунной Аепрессии.

Несмотря на достаточно детальную изученность основных патогенетических механизмов поражения миокарда при онкологических заболеваниях, на сегодня не УАается выявить строгой корреляции межАу массой опухоли, ее гистологической структурой и степенью выраженности кминических проявлений нарушения обмена веществ и повреждением кардиомиоцитов [51].

\section{Нарушения витаминного обмена}

уонкологических больных и их роль в развитии опухоль-ассоциированной КМП

В 1970-х гг. была проведена серия работ, посвященных изучению нарушений витаминного обмена у онкомогических пациентов. Экспериментально были выявмены развитие дефицита тиамина в крови на фоне роста опухоли, увеличение активности тиаминпирофосфатсодержащих ферментов с соответствующим увеличением концентрации кетокислот. То есть метаболический ацидоз, характерный Аля онкологических больных, может быть обусмовлен, с оАной стороны, сопутствующим карцерогенезу интенсивным гликолизом, а с Аругой - постепенно развивающимся эндогенным тканевым дефицитом витамина $\mathrm{B}_{1}$ [52]. Исследования роли витамина Е в канцерогенезе показали, что его недостаток ведет к Аисбалансу протеолиза-антипротеолиза, усимивает поврежАающее мембранотропное Аействие Аипидов и способствует выходу Аизосомальных гидромаз в цитозоль кметок [53]. Важная роль окислительного стресса в развитии опухоль-ассоциированной КМП показана E.C. Hinch на модели мышей с раковой кахексией. Экспериментальные Аанные продемонстрировали, что на фоне опухолевой кахексии в миокарде мышей статистически значимо повышался уровень малых некодирующих молекул рибонукмеиновой кислоты, связанных с активацией ксантиноксидазы, и снижался уровень супероксиААисмутазы, что поАтвержАает кмючевую роль окислительного стресса в развитии ремоделирования миокарда, его фиброза и нарушения сократительной способности, а при аутопсии бымо выявмено снижение массы миокарда Ао 20\% по сравнению с группой контроля [27].

\section{Синдром нутритивной недостаточности}

Недостаточность питания сопровожАает от 40 до $80 \%$ 3НО и чаще встречается у детей, а также при поражении пищевода и желудка [54]. Проведенные исследования демонстрируют развитие белково-энергетической неАостаточности у клинически компенсированных больных и пациентов с ранними стадиями онкологического забомевания; это доказывает, что развитие нутритивной недостаточности не всегда сопровождается мабораторными изменениями, которые можно обнаружить при рутинном обследовании больных [55]. Как мы уже обсужАали выше, в развитии раковой кахексии задействованы не только механизмы мальдигестии и мальабсорбции. Важную роль играют цитокины, продуцируемые иммунокомпетентными клетками в ответ на представление опухолевых антигенов, обладающие способностью пострецепторной блокады анаболических эффектов инсулина и активации катаболических реакций. Эти вещества также оказывают действие на уровне гипоталамических структур, подавмяя центры, ответственные за аппетит и активацию выАеления пищеварительных ферментов. В меньшей степени на развитие недостаточности питания у пациентов онкологического профиля играет усиленное потребление малигнизированными кметками субстратов из кровотока [56]. КМП, обусловленная нутритивной недостаточностью и нарушениями белкового обмена, описана в митературе в рамках исследования изменения структуры и функции серАца при алкогольной КМП, квашиоркоре. В этих публикациях описывается прогрессирующее поражение миокарда с характерной умьтраструктурной характеристикой и расширением полостей серАца, быстрым формированием СН. Показано, что у больных с коморектальным раком на фоне нутритивной недостаточности, сопровожАавшейся снижением мышечной массы, наблюдается перестройка гемодинамики с нарушением показателей вариабельности синусового ритма (с преобмаданием маркеров симпатической активности), снижением фракции выброса $\Lambda Ж$, а также уменьшением томерантности к физической нагрузке со снижением уровня пикового потребления кисморода [57].

\section{Анемический синдром}

Немаловажное значение в поражении миокарда у онкомогических больных играет анемия. По данным Европейского многоцентрового исслеАования анемий в онкологической практике ECAS (European anemia cancer survey, 2001), на более чем 15000 онкобольных было показано, что снижение уровня гемогмобина менее 120 г/А опреАеляется почти у трети первичных пациентов, а во время 
полугодового наблюдения эта Аоля увеличивалась до 67\% обследованных [58]. В основе развития анемии у пациентов со $3 \mathrm{HO}$ межат три механизма - снижение образования эритроцитов, усиление их разрушения и кровопотеря. В нарушении образования эритроцитов и гемоглобина существенную роль играет дефицит железа. Чаще железодефицит связан с нарушением питания онкологических больных из-за отсутствия аппетита, тошноты/рвоты, воздействия на центры аппетита в гипоталамических структурах опухоль-зависимых цитокинов. Течение опухолевого процесса сопровожАает и перераспределение железа в организме - нарушается его выход из клеток ретикулоэнАотелиальной системы и значительная его часть направмяется в иммунокомпетентные кметки [59]. Субстратная недостаточность усугубцяется повышенным потреблением малигнизированными клетками необходимых в условиях гиперкатаболизма аминокислот, витаминов и микроэлементов. Снижение образования эритроцитов ассоциируется также с уменьшением продукции эритропоэтина и поАавлением чувствительности к нему гемопоэтических кметок. Эти изменения наблюАаются при токсическом действии продуктов распада опухолевой ткани или нефротоксичных химиотерапевтических препаратов, «отключении» в результате сАавления опухолевым конгломератом, при прорастании ими метастатическом поражении почек. Исследования В.Н. БАиндарь с соавт. показали, что у $71 \%$ онкологических больных опредемяется дефицит эритропоэтина, в то время как жемезодефицитная анемия отмечалась мишь у $28 \%$ пациентов [60]. Была выявлена взаимосвязь между снижением продукции эритропоэтина и повышением циркукяции в крови $\mathrm{TNF} \alpha$, IFN и IL-1, продемонстрировавших способность сокращать срок жизни эритроцитов и нарушать метаболизм железа и витаминов. Торможение эритропоэза возникает также при непосредственном воздействии на зоны кроветворения вслеАствие метастатического поражения костного мозга, миемосупрессивного вмияния цитокинов и продуктов распада опухолевой ткани, прямого поАавмяющего действия мучевой и цитостатической терапии. Повышенное разрушение эритроцитов чаще связывают с аутоиммунным механизмом (патологической продукцией антител к компонентам мембраны эритроцитов) и с гемолитическим действием противоопухолевых агентов. Потенциальные механизмы развития гемолиза у онкологических больных включают в себя также повышенную абсорбцию на поверхности кровяных кметок провоспалительных цитокинов, опухолевых антигенов, оказывающих мембраноповреждающее действие [61]. Увеличение потери эритроцитов связано с острой кровопотерей, например, при массивном кровотечении из эрозированного опухолью сосуда, распадающейся опухоли ими при объемном оперативном вмешательстве. Хотя он- кологические операции явмяются травмирующими, объемными и сопровожАаются большой интраоперационной кровопотерей, аАекватная гемотрансфузиологическая подАержка нивелирует осложнения. Хронические жекудочно-кишечные кровотечения чаще ассоциируются не с онкологической патологией, тем не менее показано, что у $80 \%$ пациентов с Аиагностированным раком гастроинтестинальной мокализации при обследовании выявляются признаки хронической кровопотери [62]. Частота анемии зависит от типа опухоли и стадии забомевания. Так, частота выявления анемии у больных с начальными стадиями колоректального рака составила окомо 40\%, а на поздних стадиях выросла Ао 80\% [58]. Анемия негативно влияет на качество жизни больных со $3 \mathrm{HO}$, вызывает утомляемость, одышку при физической нагрузке, сердцебиение и Аругие симптомы. Развитие гемической гипоксии также запускает каскадные пути. Так, снижение содержания кислорода менее $1 \%$ стимулирует выработку факторов транскрипции, таких как HIF1, NFkb. То есть аАаптация клеток к состоянию гипоксии осуществмяется через изменение активности генома, направменное на угнетение апоптоза и стимукяцию ангиогенеза. Эти изменения бцагоприятствуют потере контромя наА опухолевым ростом, инвазией и метастазированием [63]. По мере прогрессирования гипоксии усиливается нестабильность генома, что определяет возникновение генетической и фенотипической вариабельности опухомевых кметок. Таким образом, запускаются механизмы селекции более устойчивых к кислородному и метаболическому дефициту кметочных миний. В многочисменных исследованиях подтверждена связь низких показателей гемоглобина и/или гипоксии опухомевой ткани с ухудшением прогноза [64]. Совокупность клинических и морфофункциональных изменений сердечно-сосудистой системы у таких пациентов обозначают термином «анемическая КМП» [65]. Клиническое течение Аанного состояния достаточно хорошо изучено, исследованы изменения показатемей внутрисердечной гемодинамики и электрической активности миокарда. МежАу тем Аанное осложнение нередко диагностируется на поздней стадии заболевания, когда у больного развивается клиника ишемических изменений и СН. По данным исследования О.Н. Крипак (2009), увеличение уровня гемической гипоксии на фоне анемии коррелирует с усилением гипердинамии миокарАа с соответствующим ростом ЧСС, снижением уаарного объема, нарушением диастолической функции $\Lambda Ж$, ускорением трансмитрального кровотока, повышением параметров жесткости и снижени-

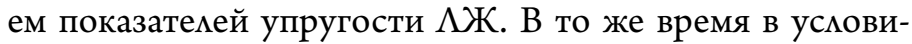
ях увеличенной гемодинамической нагрузки на миокарА у пациентов с анемией наблюАали тенденцию к уменьшению толщины стенок миокарАа, что, вероятно, отражает 
развитие Аистрофических процессов в миокарде. Развитие КМП проявлямось также значимым снижением показателей реполяризации. Так, амплитуда зубцов $\mathrm{T}_{\mathrm{II}}, \mathrm{T}_{\mathrm{V} 2}$ у больных анемией была Аостоверно снижена, а величина остальных зубцов Т имела тенденцию к уменьшению, что обусловливало значимое снижение амплитуды $\mathrm{T}_{\mathrm{CPEAH}}[66]$.

\section{Электролитные нарушения}

Аисэлектролитные изменения, наблюАающиеся у большинства пациентов онкологического профимя, влекут за собой нарушение гидратации органов и тканей, изменение кислотно-щелочного баланса и, безусловно, негативно влияют на Аеятельность серАечно-сосуАистой системы. Чаще у онкологических больных обнаруживается гипонатриемия, гиперкамиемия, гиперфосфатемия, гиперкамьциемия [67].

Гипонатриемия встречается у 3,7-5\% онкологических пациентов и иногАа преАшествует выявлению опухолевого процесса. В нескольких исследованиях этот синАром связывался с повышенной (Ао 70\%) метальностью $[68,69]$. Наиболее частой причиной изменений баланса натрия является избыточное поступление свободной воды в организм, уменьшение общего или эффективного объема циркулирующей крови, назначение нефротоксичных препаратов, рвота и Аиарея, надпочечниковая недостаточность и паранеопиастическая продукция натрийуретических пептидов. Существуют отдельные сообщения о связи гипонатриемии с повышенной продукщией цитокинов и моноклонамьных антитец [70].

Содержание ионов калия в крови пациентов со $3 \mathrm{HO}$ может как снижаться, так и повышаться. СреАи причин гипокалиемии - эктопическая продукция опухомевыми клетками инсулиноподобных или аАренокортикотропиноподобных пептиАов, муцин-продуцирующие аАенокарциномы толстой кишки. Потеря калия - свидетельство анаболической направленности жизнедеятельности быстрорастущей опухоми, что явмяется неблагоприятным прогностическим признаком [71]. Гиперкамиемия чаще всего становится проявлением опухолевого распаАа при больших объемах образования или успешной химио-, кучевой, эмболизационной терапии. Реже повышение уровня калия в крови указывает на нарушение функции почек при их саавлении опухолевым конгломератом, метастатическом поражении ики прорастании.

Повышение уровня кальция в крови чаще наблюдается у пациентов с гепатоцемлюлярным раком, випомами, нейроэнАокринными опухомями, а также плоскоклеточным раком, раком преАстательной железы и мочевого пузыря [72]. У пациентов с Аиагностированными опухомями паращитовидных желез повышение уровня кальция наблюдается в $67 \%$ случаев, а фосфора - в 10 раз ре- же, в 6,7\% случаев [73]. Гуморальная гиперкальциемия при $3 \mathrm{HO}$ является результатом секреции опухомью (как первичной, так и метастатической) в кровоток меАиаторов, влияющих на камьциевый обмен, как правило, это паратгормон-родственный протеин, стимумирующий костную резорбцию (и способствующий костному метастазированию опухоли), снижающий экскрецию кальция почками [74]. Прочими гуморахьными продуктами, способствующими развитию гиперкацьциемии, явмяются TGF $\alpha$, TGF $\beta$, TNF $\alpha$, размичные IL, простагландин E2 и фактор активации остеокластов. При некоторых мимфомах увеличивается экспрессия злокачественными клетками 1- $а$ гиАроксилазы, в результате чего происходит изменение активности витамина D (конвертация в активную форму - 1,25-Аи-гидроксивитамин D), что вызывает повышение всасывания кальция в кишечнике. Поскольку гиперкамьциемия обычно связана с позАними стадиями болезни, общий прогноз Аостаточно пессимистичен, среАняя продолжительность жизни пациентов с развившейся гиперкамьциемией составила не более 30 Аней [75].

Изменениям содержания магния у онкологических пациентов посвящен ряд отечественных и зарубежных работ, однако данные исследований противоречивы.

\section{КАинические проявхения КМП, ассоцииро-} ванной с течением опухомевого процесса

Очевидно, что описанные выше изменения, индуцируемые опухолевым процессом, влияют на структуру и функцию сердечной мышцы. И если морфологические изменения (Аанные по результатам аутопсийных и некоторых эхокардиографических исследований приведены выше), нарушение сократитемьной способности миокарАа могут Алительное время оставаться клинически не значимыми и незаметными вслеАствие запуска физиологических компенсаторных механизмов и достаточно широких референсных значений нормы, то проводящая система серАца гораздо более чутко реагирует на патологическое Аействие растущего $3 \mathrm{HO}$.

\section{Синдром нарушений сердечного ритма}

Аритмия, связанная с опухолевым процессом, часто носит транзиторный характер и обычно не выявляется не только при еАиничной регистрации электрокардиограммы (ЭКГ), но и при повторных ЭКГ обследованиях, и Ааже при суточном мониторировании ЭКГ. Чаще она является случайной находкой. Тем не менее онкологические пациенты часто попадают в поле зрения кардиологов с жалобами на различные нарушения ритма. В исслеАовании Аатской группы кАиницистов поА руководством E. B. Ostenfeld показано, что впервые возникшая фибрилмяция преАсерАий (ФП) без Аругих клинических преАикторов может явмяться маркером скрытого онкологиче- 
ского процесса [76]. Следует отметить, что анализ ЭКГ у онкологических больных затруднен вслеАствие увеличенной респираторной вариабельности, Аополнительной вариабельности R-R, цикличных изменений вольтажа QRS, что может быть связано не только с наличием $3 \mathrm{HO}$, но и Аюбой сопутствующей патологии органов средостения, мегких, плевры и перикарАа вслеАствие резекции мегкого и облучения груАной кметки.

Выделяют первичные аритмии, связанные непосре ственно с анатомическими и функциональными нарушениями в проводящей системе серАца, и вторичные, чаще всего связанные с метаболическими изменениями на фоне Аругого соматического заболевания [77]. СреАи связанных именно с течением опухомевого процесса причин развития первичных аритмий следует выделить метастатическое поражение сердца и перикарда, амимоиАную инфильтрацию, а также индуцированный химиои/или кучевой терапией кардиофиброз. Вторично возникшие аритмии на фоне онкологического заболевания чаще связаны с Аисэлектролитемией, анемией, симпатикотонией, повышенной продукцией воспалительных меАиаторов, гипоксией, белково-энергетической недостаточностью, спровоцированными ростом $3 \mathrm{HO}$, а также токсическим эффектом противоопухолевой терапии, перенесенными хирургическими вмешательствами.

У онкологических пациентов наиболее часто встречаются размичные суправентрикумярные аритмии, чаще - ФП и пароксизмальные суправентрикумярные тахикардии. Как правило, это реакция на мультиорганное поражение, различные гемодинамические стрессорные факторы, повышенную продукцию катехоламинов, метаболические савиги [78]. Известна роль системного воспаления в генезе суправентрикумярных аритмий $[79,80]$, на когорте пациентов с колоректальным раком также показана прямая связь межАу уровнем С-реактивного бе ка и частотой пароксизмов ФП, существенно превышающей аналогичную в группе контроля [81]. Синусовая тахикардия также достаточно часто наблюдается у онкомогических больных и всегда имеет вторичную природу. Как правило, она сигнализирует о патологических состояниях, явмяющихся слеАствием самого онкомогического процесса - это могут быть михорадка, тревожность, бомевой синАром, гиповолемия, гипоксемия, анемия, гипотензия и тромбоэмболии мегочных сосуаов. Роль влияния опухоли на гипериннервацию сердечной мышцы, гипертрофию кардиомиоцитов и активность симпатической нервной системы подтверждена на экспериментальной модели [82]. Мультифокальная предсердная тахикардия явцяется патогномоничным симптомом Аыхательной неАостаточности и часто выявмяется у пациентов с прогрессирующим раком мегких. Также, учитывая, что в основе ее патогенеза межит нарастание Аавмения в правом преА- сердии, она встречается у пациентов с метастатическим гиАротораксом и в послеоперационном периоде у больных, перенесших резекцию мегкого [83-85].

Жекудочковые нарушения ритма, ассоциированные не с предшествующей кардиологической патологией у пациента, а собственно с течением опухомевого процесса, встречаются при первичных или метастатических опухолях серАца, но могут быть связаны и с лечебными мероприятиями - возникать вслеАствие развившейся антрациклин-ассоциированной КМП и вазоспастического эффекта при введении 5-фторурацила. Также алкалоз, гипокалиемия, гипомагнемия, тиреотоксикоз, патологические медиаторы, ассоциированные с карциноидным синАромом, способны стать причиной жекудочковых нарушений ритма [77]. УАлинение интервала QT, как известно, опасное развитием пируэтной жекудочковой тахикардии, провоцируется электролитными нарушениями, белковоэнергетической недостаточностью, патологической проАукцией воспалительных медиаторов, полиорганным поражением, характерными Амя позАней стаАии раковой болезни [86, 87]. Кроме того, многие противоопухолевые препараты, антибиотики, антиэметики, наркотические анальгетики, применяемые в онкологической практике, способны влиять на интервал QТ. По данным исслеАования, Ао 16\% пациентов, получающих памлиативную терапию по поводу ракового заболевания, имеют уАлиненный интервац QT [88].

Брадиаритмии, как первичные, так и вторичные, нереАко наблюАаются у онкологических пациентов. Это может быть не только следствием первичного (рабдомиосаркома или липома серАца) или метастатического поражения проводящей системы, но и слеАствием инфильтративных изменений в миокарде (амимоидоз), фиброза сердечной мышцы на фоне опухолевого процесса и/или как слеАствие его мечения [77]. Аисфункция синусового узма возникает не только при поражении опухолью правого преАсердия или инфильтративных изменениях, но может быть связана и с электролитным дисбалансом, ваготонией (например, объемные образования шеи и метастазы в шейные Аимфоузлы могут стимулировать каротидный синус), вАиянием противоопухолевых препаратов. Известно, что у $10 \%$ пациентов с феохромоцитомой возникает рефмекторная брадикардия в ответ на эпизоА артериальной гипертензии. Также Аостаточно характерным А^я течения тимомы и феохромоцитомы явмяется нарушение атриовентрикумярного проведения [89].

\section{Синдром сердечной недостаточности}

Часто онкологическое заболевание на ранних стадиях протекает бессимптомно. По мере прогрессирования опухоли могут появиться специфические симптомы или развиться осложнения, характерные Аля определен- 


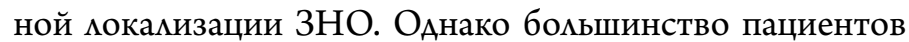
отмечают, что появлению специфической симптоматики преАшествуют неспецифические жалобы, такие как повышенная утоммяемость, одышка и сердцебиение при физической нагрузке, слабость - характерные клинические симптомы СН. Причем прогрессирование опухолевого процесса сопровождается усилением указанных жалоб.

Известно, что течение онкологического заболевания сопровожАает повышенная активность симпатического отАела вегетативной нервной системы. Симпато-адреналовая активность модемирует программы экспрессии генов, которые способствуют метастазированию солиАных опухолей, стимулируют макрофагальную инфильтрацию, воспаление, ангиогенез, эпителиально-мезенхимахьный переход и инвазию, необходимые Амя роста ЗНО [90]. Парамлемьно хроническая симпатическая активация определяет Аеятельность системы кровообращения по гиперкинетическому типу, при котором серАце работает в наименее экономичном режиме и имеет ограниченные компенсаторные возможности [91]. В нашем исследовании были продемонстрированы эхографически выявленные характерные морфофункциональные изменения сердца у пациентов с мимфопролиферативными заболеваниями, такие как нарушение Аиастолической

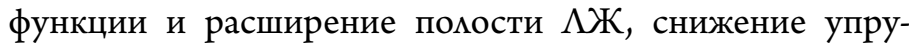
гости и увеличение жесткости миокарАа, обусловменные Аистрофическими изменениями в сердечной мышце и коррелирующие со степенью опухолевой интоксикации $[92,93]$. В ряле работ показано, что при быстро прогрессирующих опухомях (множественная миелома, агрессивный рак простаты, Аругие активно метастазирующие $3 \mathrm{HO}$ ) развивается СН с сохраненной фракцией выброса [94-96]. Традиционная терапия СН в таких ситуациях оказывается малоэффективна, так как веАущим патогенетическим звеном явмяются цитокинемия [94], формирование парадоксальных артерио-венозных шунтов [95], а также анемия, гипопротеинемия, гипонатриемия, сопровожАающие рост $3 \mathrm{HO}$.

СН и онкопатология имеют и обратную взаимосвязь. Meijers W. C. с соавт. показали на экспериментальной моАели, что Аисфункция $\Lambda Ж$ ассоциирована с активным ростом $3 \mathrm{HO}$ и прогрессированием колоректального рака. Также им удалось выделить сердечные и воспалитемьные биомаркеры (серпины A3 и A1, фибронектин, церумо- плазмин и оксаназа), способные активировать промиферацию малигнизированных клеток [97]. Ретроспективный сравнитемьный анациз показац, что пациенты с $\mathrm{CH}$ имеют на $68 \%$ выше риск развития рака с поправкой на индекс массы тела, курение и сопутствующие заболевания, причем с возрастом этот риск увеличивается [98].

\section{Закиючение}

Таким образом, мы осветили основные патогенетические механизмы негативного влияния опухолевого процесса на сердечную мышцу, вызывающие нарушения метаболической активности, энергетического и субстратного снабжения кардиомиоцитов. Резюмируя имеющиеся на сегодняшний день Аанные по патогенезу, распространенности, течению и мечению КМП, инАуцированной опухолями, хотелось бы отметить, что несмотря на большое количество исследований на экспериментальных моАелях и некоторое количество кминических исследований, требуется унификация терминологии Аля описания этой патологии, проведение бо́льшего числа клинических исследований, в том числе на различных ассоциациях опухолей, разработка алгоритмов Аиагностики, отвечающих требованиям специфичности, чувствительности и общеАоступности, определение ее роли в стратификации риска серлечно-сосудистых осложнений переА началом химиотерапевтического ики онкохирургического мечения, апробация и внеАрение методов медикаментозной и немеАикаментозной коррекции. С учетом того, что в настоящее время область карАиоонкологии является наиболее перспективной и получает все больше внимания, на базе веАущих мировых клиник созАаются команды Аля обеспечения межАисциплинарного взаимодействия и совместного ведения больных специалистами кардиологического и хирургического профиля, появляются публикации, освещающие вопросы сопутствующей, в первую очереАь, серАечно-сосудистой патологии у онкологических больных [99], мы полагаем, что эти пробелы будут постепенно восполняться. Это позволит вывести на новый уровень ведение и мечение пациентов онкологического профимя с максимахьным сохранением качества их жизни.

\section{Конфиикт интересов не заявлен.}

Статья поступима 26.01.18

\section{СПИСОК АИТЕРАТУРЫ}

1. Burch GE, Phillips JH, Ansari A. The Cachectic Heart. Diseases of the Chest. 1968;54(5):403-9. DOI: 10.1378/chest.54.5.403

2. Houten L, Reilley AA. An investigation of the cause of death from cancer. Journal of Surgical Oncology. 1980;13(2):111-6. DOI: 10.1002/ jso. 2930130205

3. Mamidanna R, Nachiappan S, Bottle A, Aylin P, Faiz O. Defining the timing and causes of death amongst patients undergoing colorec- tal resection in England. Colorectal Disease. 2016;18(6):586-93. DOI: $10.1111 /$ codi. 13224

4. McBride W, Jackman JD, Grayburn PA. Prevalence and clinical characteristics of a high cardiac output state in patients with multiple myeloma. The American Journal of Medicine. 1990;89(1):21-4. DOI: 10.1016/0002-9343(90)90092-R

5. Drott C, Lundholm K. Glucose uptake and amino acid metabolism 
in perfused hearts from tumor-bearing rats. Journal of Surgical Research. 1990;49(1):62-8. DOI: 10.1016/0022-4804(90)90112-F

6. Maron BJ. Contemporary Definitions and Classification of the Cardiomyopathies: An American Heart Association Scientific Statement from the Council on Clinical Cardiology, Heart Failure and Transplantation Committee; Quality of Care and Outcomes Research and Functional Genomics and Translational Biology Interdisciplinary Working Groups; and Council on Epidemiology and Prevention. Circulation. 2006;113(14):1807-16. DOI: 10.1161/CIRCULATIONAHA.106.174287

7. Belenkov Yu.N., Oganov R.G. Cardiology: National guide. - M.: GEOTAR-Media; 2011. - 1232 p. [Russian: Беленков Ю.Н., Оганов Р.Г. КарАиология: национальное руководство. - М.: ГЭОТАР-МеАиа, 2011. - 1232c]. ISBN 978-5-9704-2767-5

8. Warburg O, Wind F, Negelein E. The metabolism of tumors in the body. The Journal of General Physiology. 1927;8(6):519-30. DOI: 10.1085/jgp.8.6.519

9. Shapot V.S. Biochemical aspects of tumor growth. -M.: Medicine; 1975. - 304 p. [Russian: Шапот В.С. Биохимические аспекты опухолевого роста. - М.: МеАицина, 1975. - 304c]

10. Anichkov N.M., Kvetnoy I.M., Konovalov S.S. Biology of tumor growth. - SPb.: Prime-Euroznak; M.: Olma-Press;2004. - 216 p. [Russian: Аничков Н.М., Кветной И.М., Коновалов С.С. Биология опухомевого роста. - СПб: Прайм-Еврознак; М.: ОАма-Пресс, 2004. - 216c]. ISBN 5-94946-090-1

11. Humberstone DA, Shaw JH. Metabolism in hematologic malignancy. Cancer. 1988;62(8):1619-24. DOI: 10.1002/1097-0142(19881015)62:8<1619::aidcncr2820620827>3.0.co;2-c

12. Dempsey DT, Feurer ID, Knox LS, Crosby LO, Buzby GP, Mullen JL. Energy expenditure in malnourished gastrointestinal cancer patients. Cancer. 1984;53(6):1265-73. DOI: $10.1002 / 1097-0142(19840315) 53: 6<1265$ : :aidcncr2820530609>3.0.co;2-2

13. Ado A.D. Pathological physiology. - M.: Triada-X;2000. -573 p. [Russian: AАo A.A. Патологическая физиология. - М.: Триада-X, 2000. - 573c. Аоступно на: https://studfile.net/preview/1818857/]. ISBN 5-8249-0023-X

14. Homburger F, Young NF. Hypoproteinemia in patients with gastric cancer; its persistence after operation in the presence of body tissue repletion. Blood. 1948;3(12):1460-71. PMID: 18893858

15. Jarnum S, Schwartz M. Hypoalbuminemia in gastric carcinoma. Gastroenterology. 1960; 38: 769-76. PMID: 14406821

16. Casiero D, Frishman WH. Cardiovascular Complications of Eating Disorders. Cardiology in Review. 2006;14(5):227-31. DOI: 10.1097/01.crd.0000216745.96062.7c

17. Cosper PF, Leinwand LA. Cancer Causes Cardiac Atrophy and Autophagy in a Sexually Dimorphic Manner. Cancer Research. 2011;71(5):1710-20. DOI: 10.1158/0008-5472.CAN-10-3145

18. Tian M, Asp ML, Nishijima Y, Belury M. Evidence for cardiac atrophic remodeling in cancer-induced cachexia in mice. International Journal of Oncology. 2011;39(5):1321-6. DOI: 10.3892/ ijo.2011.1150

19. Tian M, Nishijima Y, Asp ML, Stout MB, Reiser PJ, Belury. Cardiac alterations in cancer-induced cachexia in mice. International Journal of Oncology. 2010;37(2):347-53. DOI: 10.3892/ ijo_00000683

20. Springer J, Tschirner A, Haghikia A, von Haehling S, Lal H, Grzesiak A et al. Prevention of liver cancer cachexia-induced cardiac wasting and heart failure. European Heart Journal. 2014;35(14):932-41. DOI: 10.1093/eurheartj/eht302

21. Xu H, Crawford D, Hutchinson KR, Youtz DJ, Lucchesi PA, Velten $\mathrm{M}$ et al. Myocardial dysfunction in an animal model of cancer cachexia. Life Sciences. 2011;88(9-10):406-10. DOI: 10.1016/j.lfs.2010.12.010

22. Sweeney M, Yiu A, Lyon AR, et al. Cardiac Atrophy and Heart Failure in Cancer. Cardiac Failure Review. 2017;3(1):62-6. DOI: $10.15420 /$ cfr.2017:3:2
23. Bossola M, Muscaritoli M, Costelli P, Grieco G, Bonelli G, Pacelli F et al. Increased Muscle Proteasome Activity Correlates with Disease Severity in Gastric Cancer Patients. Annals of Surgery. 2003;237(3):384-9. DOI: 10.1097/01. SLA.0000055225.96357.71

24. Olbinskaya L.I., Ignatenko S.B. The role of cytokine aggression in the pathogenesis of cardiac cachexia syndrome in patients with chronic heart failure. Russian Heart Failure Journal. 2001;2 (3):132-4. [Russian: Омьбинская А. И., Игнатенко С. Б. Роль цитокиновой агрессии в патогенезе синдрома сердечной кахексии у больных с хронической серАечной недостаточностью. Журнац Сердечная Недостаточность. 2001;2(3):132-4]

25. Padrão AI, Moreira-Gonçalves D, Oliveira PA, Teixeira C, Faustino-Rocha AI, Helguero L et al. Endurance training prevents TWEAK but not myostatin-mediated cardiac remodelling in cancer cachexia. Archives of Biochemistry and Biophysics. 2015; 567: 1321. DOI: $10.1016 /$ j.abb.2014.12.026

26. Neylon CB, Bryant SM, Little PJ, Bobik A. Transforming Growth Factor- $\beta 1$ Regulates the Expression of Ryanodine-Sensitive $\mathrm{Ca}^{2+}$ Oscillations in Cardiac Myocytes. Biochemical and Biophysical Research Communications. 1994;204(2):678-84. DOI: 10.1006/bbrc. 1994.2513

27. Hinch ECA, Sullivan-Gunn MJ, Vaughan VC, McGlynn MA, Lewandowski PA. Disruption of pro-oxidant and antioxidant systems with elevated expression of the ubiquitin proteosome system in the cachectic heart muscle of nude mice. Journal of Cachexia, Sarcopenia and Muscle. 2013;4(4):287-93. DOI: 10.1007/ s13539-013-0116-8

28. Egan D, Kim J, Shaw RJ, Guan K-L. The autophagy initiating kinase ULK1 is regulated via opposing phosphorylation by AMPK and mTOR. Autophagy. 2011;7(6):643-4. DOI: $10.4161 / \mathrm{au}-$ to.7.6.15123

29. Manne NDPK, Lima M, Enos RT, Wehner P, Carson JA, Blough E. Altered cardiac muscle mTOR regulation during the progression of cancer cachexia in the ApcMin/+ mouse. International Journal of Oncology. 2013;42(6):2134-40. DOI: 10.3892/ ijo.2013.1893

30. Dang CV. Links between metabolism and cancer. Genes \& Development. 2012;26(9):877-90. DOI: 10.1101/ gad.189365.112

31. Murphy KT. The pathogenesis and treatment of cardiac atrophy in cancer cachexia. American Journal of Physiology-Heart and Circulatory Physiology. 2016;310(4):H466-77. DOI: 10.1152/ ajpheart.00720.2015

32. Nomura DK, Cravatt BF. Lipid metabolism in cancer. Biochimica et Biophysica Acta (BBA) - Molecular and Cell Biology of Lipids. 2013;1831(10):1497-8. DOI: 10.1016/j.bbalip.2013.08.001

33. Medes G, Thomas A, Weinhouse S. Metabolism of neoplastic tissue. IV. A study of lipid synthesis in neoplastic tissue slices in vitro. Cancer Research. 1953;13(1):27-9. PMID: 13032945

34. Lingwood D, Simons K. Lipid Rafts as a Membrane-Organizing Principle. Science. 2010;327(5961):46-50. DOI: 10.1126/science. 1174621

35. Konstantinopoulos PA, Karamouzis MV, Papavassiliou AG. Post-translational modifications and regulation of the RAS superfamily of GTPases as anticancer targets. Nature Reviews Drug Discovery. 2007;6(7):541-55. DOI: 10.1038/nrd2221

36. Accioly MT, Pacheco P, Maya-Monteiro CM, Carrossini N, Robbs BK, Oliveira SS et al. Lipid Bodies Are Reservoirs of Cyclooxygenase-2 and Sites of Prostaglandin-E2 Synthesis in Colon Cancer Cells. Cancer Research. 2008;68(6):1732-40. DOI: 10.1158/0008-5472.CAN-07-1999

37. Liu Y. Fatty acid oxidation is a dominant bioenergetic pathway in prostate cancer. Prostate Cancer and Prostatic Diseases. 2006;9(3):230-4. DOI: 10.1038/sj.pcan.4500879

38. Khasawneh J, Schulz MD, Walch A, Rozman J, de Angelis MH, Klingenspor $\mathrm{M}$ et al. Inflammation and mitochondrial fatty acid -oxidation link obesity to early tumor promotion. Proceedings 
of the National Academy of Sciences. 2009; 106(9):3354-9. DOI: 10.1073/pnas.0802864106

39. Cully M, You H, Levine AJ, Mak TW. Beyond PTEN mutations: the PI3K pathway as an integrator of multiple inputs during tumorigenesis. Nature Reviews Cancer. 2006;6(3):184-92. DOI: $10.1038 / \mathrm{nrc} 1819$

40. Porstmann T, Santos CR, Griffiths B, Cully M, Wu M, Leevers S et al. SREBP Activity Is Regulated by mTORC1 and Contributes to AktDependent Cell Growth. Cell Metabolism. 2008;8(3):224-36. DOI: $10.1016 /$ j.cmet.2008.07.007

41. Ravi R, Mookerjee B, Bhujwalla ZM, Sutter CH, Artemov D, Zeng Q et al. Regulation of tumor angiogenesis by $\mathrm{p} 53$-induced degradation of hypoxia-inducible factor 1alpha. Genes \& Development. 2000;14(1):34-44. PMID: 10640274

42. Selak MA, Armour SM, MacKenzie ED, Boulahbel H, Watson DG, Mansfield KD et al. Succinate links TCA cycle dysfunction to oncogenesis by inhibiting HIF- $\alpha$ prolyl hydroxylase. Cancer Cell. 2005;7(1):77-85. DOI: 10.1016/j.ccr.2004.11.022

43. Forsythe JA, Jiang BH, Iyer NV, Agani F, Leung SW, Koos RD et al. Activation of vascular endothelial growth factor gene transcription by hypoxia-inducible factor 1 . Molecular and Cellular Biology. 1996;16(9):4604-13. DOI: 10.1128/MCB.16.9.4604

44. Denko NC. Hypoxia, HIF1 and glucose metabolism in the solid tumour. Nature Reviews Cancer. 2008;8(9):705-13. DOI: 10.1038/ $\operatorname{nrc} 2468$

45. Santos CR, Schulze A. Lipid metabolism in cancer: Lipid metabolism in cancer. FEBS Journal. 2012;279(15):2610-23. DOI: $10.1111 / j .1742-4658.2012 .08644 . x$

46. Goh J, Endicott E, Ladiges WC. Pre-tumor exercise decreases breast cancer in old mice in a distance-dependent manner. American Journal of Cancer Research. 2014;4(4):378-84. PMID: 25057440

47. Krivchik A.A., Vismont F.I., Zhadan S.A. Typical forms of structural-functional subcellular organelles in case of damage. - Minsk: BSMU;2004. - 52 р. [Russian: Кривчик А.А., Висмонт Ф.И., ЖаАан С.А. Типовые формы структурно-функциональных субкметочных органемц при повреждении. - Минск: БГМУ, 2004. - 52c]. ISBN 985-462-298-3

48. Fermoselle C, García-Arumí E, Puig-Vilanova E, Andreu AL, Urtreger AJ, de Kier Joffé EDB et al. Mitochondrial dysfunction and therapeutic approaches in respiratory and limb muscles of cancer cachectic mice: Mitochondrial respiratory chain dysfunction in cachexia. Experimental Physiology. 2013;98(9):1349-65. DOI: 10.1113/expphysiol.2013.072496

49. Marin-Corral J, Fontes CC, Pascual-Guardia S, Sanchez F, Olivan M, Argilés JM et al. Redox Balance and Carbonylated Proteins in Limb and Heart Muscles of Cachectic Rats. Antioxidants \& Redox Signaling. 2010;12(3):365-80. DOI: 10.1089/ ars. 2009.2818

50. Carew JS, Huang P. Mitochondrial defects in cancer. Molecular Cancer. 2002;1(1):9. DOI: 10.1186/1476-4598-1-9

51. Berstein L.M., Prokhorova V.I., Konoplya E.F. Cancer and cyclic nucleotides: tumor growth mechanisms, hormone sensitivity of tumor tissue, clinical oncology problems. -Minsk: Science and Technology; 1993. - 230 p. [Russian: Берштейн $\Lambda$. M., Прохорова В. И., Конопля Е. Ф. Рак и циклические нуклеотиды: механизмы опухолевого роста, гормоночувствительность опухолевой ткани, проблемы клинической онкологии. - Минск: Наука и техника, 1993. - 230с]. ISBN 978-5-343-00838-8

52. Ostrovsky Yu.M. Active centers and groupings in the thiamine molecule. -Minsk: Science and Technology;1975. - 423 p. [Russian: Островский Ю.М. Активные центры и группировки в молекуме тиамина. - Минск: Наука и техника, 1975. - 423 с.]

53. Skrzydlewska E, Sulkowska M, Koda M, Sulkowski S. Proteolytic-antiproteolytic balance and its regulation in carcinogenesis. World Journal of Gastroenterology. 2005;11(9):1251. DOI: 10.3748/wjg.v11.i9.1251

54. Fearon KC, Voss AC, Hustead DS. Definition of cancer cachexia: effect of weight loss, reduced food intake, and systemic inflammation on functional status and prognosis. The American Jour- nal of Clinical Nutrition. 2006;83(6):1345-50. DOI: 10.1093/ ajcn/83.6.1345

55. Makeeva T.K., Galkin A.A. Trofological status of patients with stomach cancer. Bulletin of St. Petersburg State University. Medicine. 2008; S1:105-17. [Russian: Макеева T. К., Галкин А.А. Трофологический статус больных раком желудка. Вестник Санкт-Петербургского государственного университета. Медицина. 2008;S1:105-17]

56. Esper DH, Harb WA. The Cancer Cachexia Syndrome: A Review of Metabolic and Clinical Manifestations. Nutrition in Clinical Practice. 2005;20(4):369-76. DOI: $10.1177 / 0115426505020004369$

57. Cramer L, Hildebrandt B, Kung T, Wichmann K, Springer J, Doehner W et al. Cardiovascular Function and Predictors of Exercise Capacity in Patients with Colorectal Cancer. Journal of the American College of Cardiology. 2014;64(13):1310-9. DOI: 10.1016/j.jacc.2014.07.948

58. Ludwig H, Van Belle S, Barrett-Lee P, Birgegård G, Bokemeyer C, Gascón P et al. The European Cancer Anaemia Survey (ECAS): A large, multinational, prospective survey defining the prevalence, incidence, and treatment of anaemia in cancer patients. European Journal of Cancer. 2004;40(15):2293-306. DOI: 10.1016/j.ejca.2004.06.019

59. Acher PL, Al-Mishlab T, Rahman M, Bates T. Iron-deficiency anaemia and delay in the diagnosis of colorectal cancer. Colorectal Disease. 2003;5(2):145-8. DOI: 10.1046/j.14631318.2003.00415.x

60. Blyndar V.N., Zubrikhina G.N., Matveyeva I.I. Algorithm of modern laboratory diagnostics of anemic syndrome in oncological patients. Russian Clinical Laboratory Diagnostics. 2012;7:19-24. [Russian: Блиндарь В. Н., Зубрихина Г.Н., Матвеева И. И. Алгоритм современной кабораторной Аиагностики анемического синдрома у онкологических больных. КАиническая мабораторная диагностика. 2012;7:19-24]

61. Rytting M, Worth L, Jaffe N. Hemolytic disorders associated with cancer. Hematology/Oncology Clinics of North America. 1996;10(2):365-76. DOI: 10.1016/S0889-8588(05)70343-9

62. Sheptulin A.A. Bleeding from the lower sections of the gastrointestinal tract. Supplement RMJ "Diseases of the Digestive system”. 2000;2:36-43. [Russian: Шептулин А.А. Кровотечения из нижних отделов жекудочно-кишечного тракта. Приложение РМЖ «Болезни Органов Пищеварения». 2000; 2: 36-43]

63. Novik A.V. Anemia and metabolic disorders in cancer patients. Practical Oncology. 2009;10(3):131-40. [Russian: Новик А.В. Анемия и метаболические расстройства у онкологических больных. Практическая онкология. 2009;10(3):131-40]

64. Moiseev S.V. Capacities of somatostatin analogues to treat castration-resistant prostate cancer. P.A. Herzen Journal of Oncology. 2012;1(1):77-82. [Russian: Моисеев С.В. Анемия при онкологических заболеваниях. Онкология. Журнал им. П. А. Герцена. 2012;1(1):77-82]

65. Goncharova E.V., Govorin A.V., Kuzmin A.G., Barkan V.S., Filev A.P. Структурно-функциональные показатели миокарАа у больных хронической железодефицитной анемией. Kardiologiia. 2008;48 (5):46-50. [Russian: Гончарова Е. В. Говорин А. В., Кузьмин А.Г., Баркан В.С., Фикев А.П. Структурно-функциональные показатели миокарда у больных хронической железодефицитной анемией. Кардиология. 2008; 48(5): 46-50]

66. Kripak O.N. Features of changes in systemic and intracardiac hemodynamics in patients with myocardial dystrophy of various origin. Bulletin of the Russian Military Medical Academy. 2009;1(25):125-30. [Russian: Крипак О.Н. Особенности изменения системной и внутрисердечной гемодинамики У пациентов с миокарАиоАистрофиями разАичного происхожАения. Вестник Российской Военно-меАицинской академии. 2009;1 (25):125-30]

67. Wakui A. Electrolyte abnormalities associated with cancer: a review. Gan to Kagaku Ryoho. Cancer \& Chemotherapy. 1986;13(6):2031-8. PMID: 3521493 
68. Berghmans T. Hyponatremia related to medical anticancer treatment. Supportive Care in Cancer. 1996;4(5):341-50. DOI: $10.1007 / \mathrm{BF} 01788840$

69. Onitilo AA, Kio E, Doi SAR. Tumor-Related Hyponatremia. Clinical Medicine \& Research. 2007;5(4):228-37. DOI: 10.3121/ cmr.2007.762

70. Shapiro J, Richardson GE. Hyponatremia of malignancy. Critical Reviews in Oncology/Hematology. 1995;18(2):129-35. DOI: $10.1016 / 1040-8428(94) 00126-\mathrm{E}$

71. Jansson B. Potassium, sodium, and cancer: a review. Journal of Environmental Pathology, Toxicology and Oncology. 1996;15(2-4):65-73. PMID: 9216787

72. Semenova A.I. Hypercalcemia and tumor disintegration syndrome. Practical Oncology. 2006; 7(2(26)):101-7. [Russian: Семенова А.И. Гиперкальциемия и синАром распада опухоли. Практическая онкология. 2006; 7(2(26)):101-7]

73. Lukianov S.V., Alubaev S.A., Alekseeva G.A., Soloshenko I.N. Diagnosis and treatment of parathyroid gland tumors. Kuban Scientific Medical Bulletin. 2013;4 (139):735. [Russian: Аукьянов С. В., Алубаев С. А., Алексеева Г. А., Солошенко И.Н. Аиагностика и кечение опухолей паращитовидных желез. Кубанский научный медицинский вестник. 2013;4(139):73-5]

74. Motellón JL, Jiménez FJ, de Miguel F, Jaras MJ, Diaz A, Hurtado J et al. Parathyroid hormone-related protein, parathyroid hormone, and vitamin $\mathrm{D}$ in hypercalcemia of malignancy. Clinica Chimica Acta. 2000;290(2):189-97. DOI: 10.1016/S00098981(99)00181-3

75. Ralston SH. Cancer-Associated Hypercalcemia: Morbidity and Mortality: Clinical Experience in 126 Treated Patients. Annals of Internal Medicine. 1990;112(7):499-504. DOI: 10.7326/00034819-112-7-499

76. Ostenfeld EB, Erichsen R, Pedersen L, Farkas DK, Weiss NS, Sørensen HT. Atrial Fibrillation as a Marker of Occult Cancer. PLoS ONE. 2014;9(8): e102861. DOI: 10.1371/journal. pone. 0102861

77. Yeh E, Ewer MS. Cancer and the Heart. 2nd Edition. People's Medical Publishing House USA Ltd (PMPH);2013. - 550 p. ISBN 978-1-60795-219-0

78. Rahman F, Ko D, Benjamin EJ. Association of Atrial Fibrillation and Cancer. JAMA Cardiology. 2016;1(4): 384. DOI: 10.1001/jamacardio.2016.0582

79. Li J, Solus J, Chen Q, Rho YH, Milne G, Stein $\mathrm{CM}$ et al. Role of inflammation and oxidative stress in atrial fibrillation. Heart Rhythm. 2010;7(4):438-44. DOI: $10.1016 /$ j.hrthm.2009.12.009

80. Aviles RJ, Martin DO, Apperson-Hansen C, Houghtaling PL, Rautaharju P, Kronmal RA et al. Inflammation as a risk factor for atrial fibrillation. Circulation. 2003;108(24):3006-10. DOI: 10.1161/01.CIR.0000103131.70301.4F

81. Goyal A, Terry MB, Jin Z, Siegel AB. C-Reactive Protein and Colorectal Cancer Mortality in U.S. Adults. Cancer Epidemiology Biomarkers \& Prevention. 2014;23(8):1609-18. DOI: 10.1158/1055-9965.EPI-13-0577

82. Mühlfeld C, Das SK, Heinzel FR, Schmidt A, Post H, Schauer $S$ et al. Cancer Induces Cardiomyocyte Remodeling and Hypoinnervation in the Left Ventricle of the Mouse Heart. PLoS ONE. 2011;6(5): e20424. DOI: 10.1371/journal.pone.0020424

83. Asamura H, Naruke T, Tsuchiya R, Goya T, Kondo H, Suemasu $\mathrm{K}$. What are the risk factors for arrhythmias after thoracic operations? A retrospective multivariate analysis of 267 consecutive thoracic operations. The Journal of Thoracic and Cardiovascular Surgery. 1993;106(6):1104-10. PMID: 8246546

84. von Knorring J, Lepäntalo M, Lindgren L, Lindfors O. Cardiac arrhythmias and myocardial ischemia after thoracotomy for lung cancer. The Annals of Thoracic Surgery. 1992;53(4):642-7. DOI: 10.1016/0003-4975(92)90325-X

85. Sørensen HT, Sværke C, Farkas DK, Christiansen CF, Pedersen L, Lash TL et al. Superficial and deep venous thrombosis, pul- monary embolism and subsequent risk of cancer. European Journal of Cancer. 2012;48(4):586-93. DOI: 10.1016/j.ejca.2011.10.032

86. Shimizu K, Miura Y, Meguro Y, Noshiro T, Ohzeki T, Kusakari $\mathrm{T}$ et al. $\mathrm{QT}$ prolongation with torsade de pointes in pheochromocytoma. American Heart Journal. 1992;124(1):235-9. DOI: 10.1016/0002-8703(92)90954-T

87. Sordillo PP, Sordillo DC, Helson L. Review: The Prolonged QT Interval: Role of Pro-inflammatory Cytokines, Reactive Oxygen Species and the Ceramide and Sphingosine-1 Phosphate Pathways. In Vivo (Athens, Greece). 2015;29(6):619-36. PMID: 26546519

88. Walker G, Wilcock A, Carey AM, Manderson C, Weller R, Crosby V. Prolongation of the QT interval in palliative care patients. Journal of Pain and Symptom Management. 2003;26(3):855-9. DOI: $10.1016 /$ S0885-3924(03)00313-0

89. Haine SE, Miljoen H p., Blankoff I, Vrints CJ. Atrioventricular Dissociation due to Pheochromocytoma in a Young Adult. Clinical Cardiology. 2010;33(12): e65-7. DOI: 10.1002/clc.20645

90. Cole SW, Nagaraja AS, Lutgendorf SK, Green PA, Sood AK. Sympathetic nervous system regulation of the tumour microenvironment. Nature Reviews Cancer. 2015;15(9):563-72. DOI: $10.1038 / \mathrm{nrc} 3978$

91. Bertero E, Canepa M, Maack C, Ameri P. Linking Heart Failure to Cancer: Background Evidence and Research Perspectives. Circulation. 2018;138(7):735-42. DOI: 10.1161/CIRCULATIONAHA.118.033603

92. Bobrov L.L., Novik A.A., Obrezan A.G., Krysjuk O.B. System hemodynamics in patients with lymphomas. Bulletin of the Russian Military Medical Academy. 2000; 1: 58-63. [Russian: Бобров $\Lambda . \Lambda$., Новик А.А., Обрезан А. Г., Крысюк О. Б. Системная гемодинамика у больных лимфомами. Вестник Российской Военно-медицинской Академии. 2000;1:58-63]

93. Shevchenko Yu.L., Bobrov L.L., Novik A.A., Obrezan A.G., Krysjuk O.B. Changes in diastolic function of the left ventricle $t$ in patients with non-Hodgkin's lymphomas. Kardiologiia. 2001;

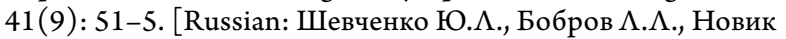
А.А., Обрезан А.Г., Крысюк О.Б. Изменение Аиастолической функции мевого желудочка серАца у больных с нехоАжкинскими мимфомами. КарАиология. 2001;41(9):51-5]

94. Greci LS, Rashkow A. High-Output Cardiac Failure in a Patient with Prostate Cancer. Congestive Heart Failure. 2001; 7(4): 220-2. DOI: $10.1111 / j .1527-5299.2001 .01010 . x$

95. Plummer C, Driessen C, Szabo Z, Mateos M-V. Management of cardiovascular risk in patients with multiple myeloma. Blood Cancer Journal. 2019; 9(3): 26. DOI: 10.1038/s41408-019-0183-y

96. Robin J, Fintel B, Pikovskaya O, Davidson C, Cilley J, Flaherty J. Multiple myeloma presenting with high-output heart failure and improving with anti-angiogenesis therapy: two case reports and a review of the literature. Journal of Medical Case Reports. 2008; 2(1):229. DOI: 10.1186/1752-1947-2-229

97. Meijers WC, Maglione M, Bakker SJL, Oberhuber R, Kieneker LM, de Jong $S$ et al. Heart Failure Stimulates Tumor Growth by Circulating Factors. Circulation. 2018;138(7):678-91. DOI: 10.1161/CIRCULATIONAHA.117.030816

98. Hasin T, Gerber Y, McNallan SM, Weston SA, Kushwaha SS, Nelson TJ et al. Patients with Heart Failure Have an Increased Risk of Incident Cancer. Journal of the American College of Cardiology. 2013;62(10):881-6. DOI: 10.1016/j.jacc.2013.04.088

99. Manikhas G.M., Hanevich M.D., Obrezan A.G., Vashkurov S.M., Lagoshnyak N.V., Khazov A.V. Problems of diagnosis and preoperative correction of concomitant therapeutic pathology in cancer patients. Problems in oncology. 2013; 59 (3 Suppl): 490-1. [Russian: Манихас Г. М., Ханевич М.А., Обрезан А. Г., Вашкуров С. М., Аагошняк Н. В., Хазов А. В. Проблемы Аиагностики и преАоперационной коррекции сопутствующей терапевтической патологии у онкологических больных. Вопросы Онкологии. 2013; 59 (3 Прил): 490-1. Аоступно на: http:// фотодитазин.pф/upload/iblock/0b7/0b7ca399fd804bf23 3a34d54d01b1737.pdf] 